\title{
Comment on "A hybrid model of self organizing maps and least square support vector machine for river flow forecasting" by Ismail et al. (2012)
}

\author{
F. Fahimi and A. H. El-Shafie \\ Department of Civil \& Structural Engineering, Universiti Kebangsaan Malaysia, UKM, Bangi, Selangor, Malaysia \\ Correspondence to: F. Fahimi (fahimi@vlsi.eng.ukm.my) and A. H. El-Shafie (elshafie@vlsi.eng.ukm.my) \\ Received: 9 June 2013 - Published in Hydrol. Earth Syst. Sci. Discuss.: 15 November 2013 \\ Revised: 29 July 2013 - Accepted: 21 June 2014 - Published: 29 July 2014
}

\begin{abstract}
Without a doubt, river flow forecasting is one of the most important issues in water engineering field. There are lots of forecasting techniques that have successfully been utilized by previously conducted studies in water resource management and water engineering. The study of Ismail et al. (2012), which was published in the journal Hydrology and Earth System Sciences in 2012, was a valuable piece of research that investigated the combination of two effective methods (self-organizing map and least squares support vector machine) for river flow forecasting. The goal was to make a comparison between the performances of self organizing map and least square support vector machine (SOM-LSSVM), autoregressive integrated moving average (ARIMA), artificial neural network (ANN) and least squares support vector machine (LSSVM) models for river flow prediction. This comment attempts to focus on some parts of the original paper that need more discussion. The emphasis here is to provide more information about the accuracy of the observed river flow data and the optimum map size for SOM mode as well.
\end{abstract}

\section{Introduction}

Recently, predicting river flow has become one of the indispensable parts of water resource management and water engineering. During recent decades, a considerable number of studies have been carried out for forecasting the river flow in different river basins, and various methods including selforganizing map have been applied to achieve more accurate and reliable results. In general, as an unsupervised learning method, the self-organizing map is a kind of artificial neural network (ANN) model for clustering and classification of input data, prediction, and also data mining (Kohonen, 1998; Alhoniemi et al., 1999; Vesanto and Alhoniemi, 2000). Ismail et al. (2012) carried out an inclusive study to improve the forecasting of river flow by using four different methods, i.e., SOM-LSSVM, autoregressive integrated moving average (ARIMA), ANN, and least squares support vector machine (LSSVM) models. However, the main contribution of this study was to improve the efficiency of the river flow prediction by employing a self-organizing map (SOM) model for clustering input data and coupling this method with LSSVM model.

They examined 516 monthly recorded flow data of Bernam River in Malaysia from the beginning of 1966 to the end of 2008. The study area of the research was about $1090 \mathrm{~km}^{2}$. They mentioned that Mann-Kendall tests were used as the input data in order to find other river flow trends. For the analysis procedure, the data were divided into training (456 monthly recorded data, equivalent to $88 \%$ of total data) and testing (60 monthly recorded data, equivalent to $12 \%$ of total data) sets. It should be noted that the data were normalized in the range of $[0.1,0.9]$. They also tested eight different input data types. Mean absolute error (MAE), root mean square error (RMSE) and correlation coefficient $(R)$ were used to evaluate the performance of models.

During the review of this study, authors found that some parts of this research might be more useful if there were more discussion on them. Consequently, the following comments are proposed to be discussed more to enhance the contributions of the original study in presenting a new and accurate hybrid model for forecasting river flow. 


\section{Comments}

To summarize, the following issues related to the authors' study should be properly addressed to clarify the points:

1. As mentioned before, in this study, authors tried to examine the performance of four different methods including the autoregressive integrated moving average (ARIMA), artificial neural network (ANN), least squares support vector machine (LSSVM) and SOMLSSVM models for forecasting Bernam River flow. They indicated that 516 monthly Bernam River flow data were chosen as the real data for developing and testing the models. In order to make a better evaluation of each model performance, the predicted and observed river flow in testing period were illustrated in Fig. 8 of mentioned paper (Fig. 1). Normally, the predicted river flow obtained from each of the four models has to be compared with a single unique observed data set. However, as can be seen in this figure the observed river flow used for comparison with the SOM-LSSVM model is different from the other observed river flow data for the other three methods.

2. In the original research, authors utilized only four map sizes including $2 \times 2,3 \times 3,4 \times 4$ and $5 \times 5$ for $\mathrm{SOM}$ models then stopped increasing the size at $5 \times 5$ and showed the results of the proposed hybrid model for training and testing sets in Table 4 of the mentioned paper (Table 1). They, therefore, indicated that $5 \times 5$ is the optimal map size and would present the best results. However, according to general trend of the results, during the testing period, more accurate results could be expected for larger map sizes, and it seems that even more optimum results might be obtained by using larger map sizes than $5 \times 5$. Moreover, based on the utilizing self-organizing map model in the water resources and hydrology field, most of the previous studies proposed larger map sizes for similar research. For example, Lin and Chen (2006) used the map size of $12 \times 12$, and in another study Abrahart and See (2000) used a map size of $8 \times 8$ to cluster the modeling domain into distinct types. As a different example, Chon et al. (1996) used a self-organizing map with a $9 \times 9$ neuron map size.

3. In Sect. 3.2 (Artificial Neural Network), the general concept of artificial neural network was presented. Three-layer Multi layer perceptrons (MLPs) were expressed through Eq. (2) and also Fig. 1. But it seems that some mentioned points should be corrected. In the proposed definition for Eq. (2), $w_{i}$ is defined two times, while it seems that the second one, which refers to the connection weights between hidden and output layer nodes, must be $w_{j}$. Moreover, after that, the most common types of $f($.$) and g($.$) are introduced in the$ text as the linear function and the Sigmoid function
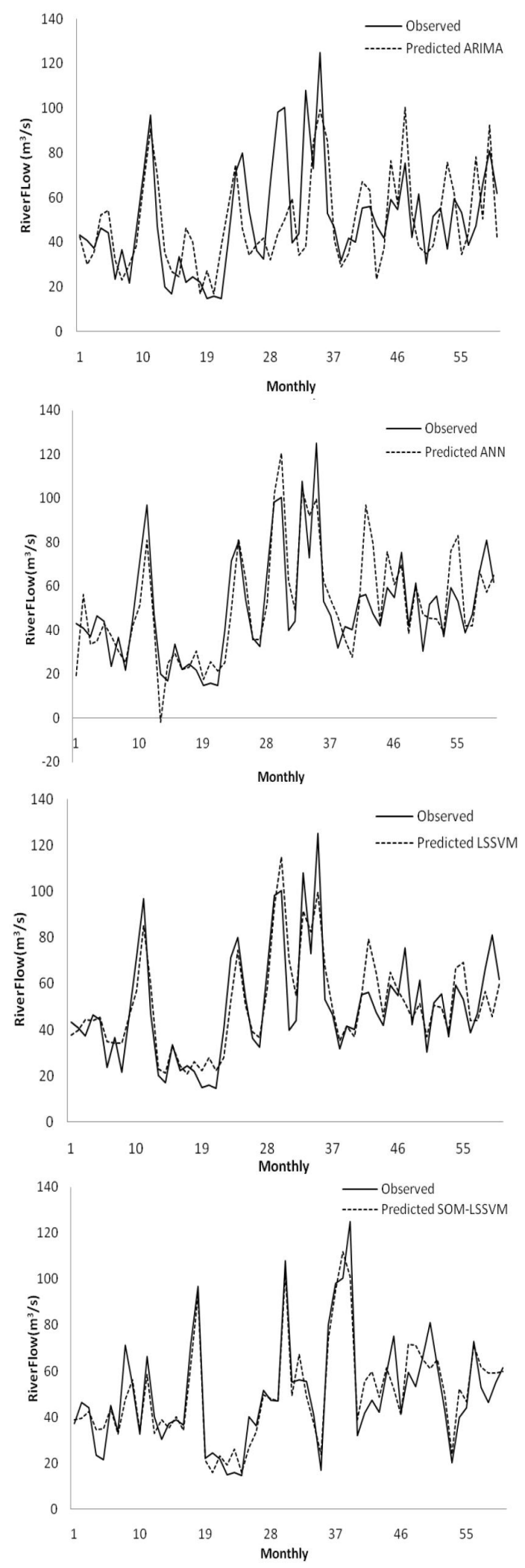

Figure 1. Predicted and observed river flow during testing period by ARIMA, ANN, LSSVM and SOM-LSSVM for Bernam River (Ismail et al., 2012). 
Table 1. The result for training and testing using a hybrid model of SOM-LSSVM for different map sizes (Ismail et al., 2012).

\begin{tabular}{|c|c|c|c|c|c|c|c|}
\hline \multirow[t]{2}{*}{ Map sizes } & \multirow[t]{2}{*}{ Data } & \multicolumn{3}{|c|}{ Testing } & \multicolumn{3}{|c|}{ Training } \\
\hline & & $R$ & RMSE & MAE & $R$ & RMSE & MAE \\
\hline \multirow{8}{*}{$2 \times 2$} & M1 & 0.7508 & 0.0872 & 0.0740 & 0.7964 & 0.0903 & 0.0680 \\
\hline & M2 & 0.6574 & 0.0963 & 0.0767 & 0.8205 & 0.0860 & 0.0655 \\
\hline & M3 & 0.6072 & 0.1020 & 0.0785 & 0.7259 & 0.1031 & 0.0758 \\
\hline & M4 & 0.6456 & 0.0975 & 0.0752 & 0.7925 & 0.0931 & 0.0686 \\
\hline & M5 & 0.6322 & 0.0988 & 0.0784 & 0.7250 & 0.1045 & 0.0770 \\
\hline & M6 & 0.5931 & 0.1022 & 0.0794 & 0.6495 & 0.1135 & 0.0869 \\
\hline & M7 & 0.6082 & 0.1011 & 0.0764 & 0.7126 & 0.1051 & 0.0758 \\
\hline & M8 & 0.8766 & 0.0620 & 0.0441 & 0.9782 & 0.0333 & 0.0212 \\
\hline \multirow{8}{*}{$3 \times 3$} & M1 & 0.7376 & 0.0860 & 0.0640 & 0.7445 & 0.0997 & 0.0747 \\
\hline & M2 & 0.7254 & 0.0879 & 0.0683 & 0.8908 & 0.0681 & 0.0532 \\
\hline & M3 & 0.7099 & 0.0917 & 0.0736 & 0.7271 & 0.1029 & 0.0760 \\
\hline & M4 & 0.7019 & 0.0908 & 0.0733 & 0.7517 & 0.0995 & 0.0736 \\
\hline & M5 & 0.6650 & 0.0951 & 0.0734 & 0.7504 & 0.1008 & 0.0721 \\
\hline & M6 & 0.5421 & 0.1067 & 0.0794 & 0.8049 & 0.0914 & 0.0685 \\
\hline & M7 & 0.6474 & 0.0971 & 0.0703 & 0.7599 & 0.0974 & 0.0735 \\
\hline & M8 & 0.8734 & 0.0622 & 0.0431 & 0.9705 & 0.0378 & 0.0278 \\
\hline \multirow{8}{*}{$4 \times 4$} & M1 & 0.8457 & 0.0691 & 0.0557 & 0.8640 & 0.0751 & 0.0537 \\
\hline & M2 & 0.7299 & 0.0884 & 0.0727 & 0.8642 & 0.0756 & 0.0561 \\
\hline & M3 & 0.6841 & 0.0937 & 0.0741 & 0.8105 & 0.0885 & 0.0649 \\
\hline & M4 & 0.6159 & 0.1010 & 0.0800 & 0.7947 & 0.0921 & 0.0696 \\
\hline & M5 & 0.7005 & 0.0916 & 0.0686 & 0.7990 & 0.0920 & 0.0647 \\
\hline & M6 & 0.6247 & 0.0992 & 0.0737 & 0.8253 & 0.0879 & 0.0645 \\
\hline & M7 & 0.7117 & 0.0894 & 0.0620 & 0.7830 & 0.0933 & 0.0701 \\
\hline & M8 & 0.8651 & 0.0647 & 0.0435 & 0.9485 & 0.0507 & 0.0348 \\
\hline \multirow{8}{*}{$5 \times 5$} & M1 & 0.7274 & 0.0876 & 0.0637 & 0.7715 & 0.0950 & 0.0659 \\
\hline & M2 & 0.7560 & 0.0838 & 0.0668 & 0.9127 & 0.0612 & 0.0446 \\
\hline & M3 & 0.7361 & 0.0865 & 0.0690 & 0.7911 & 0.0920 & 0.0646 \\
\hline & M4 & 0.7306 & 0.0870 & 0.0680 & 0.8762 & 0.0762 & 0.0550 \\
\hline & M5 & 0.6855 & 0.0931 & 0.0727 & 0.8646 & 0.0782 & 0.0555 \\
\hline & M6 & 0.7462 & 0.0850 & 0.0661 & 0.9231 & 0.0605 & 0.0385 \\
\hline & M7 & 0.6490 & 0.0969 & 0.0731 & 0.7848 & 0.0982 & 0.0761 \\
\hline & M8 & 0.9222 & 0.0492 & 0.0370 & 0.9299 & 0.0567 & 0.0401 \\
\hline
\end{tabular}

respectively, while according to Eq. (2) and Fig. 1 it seems that the Sigmoid function is the most common type of $f($.$) , and the linear function is the most com-$ mon type of $g($.$) .$

\section{Summary}

Some parts of the original study are reviewed, and the unclear points are discussed. In spite of the discussed issues and points, the mentioned study successfully proposed a new approach in river flow prediction by coupling different methods and also made an improvement in forecasting hydrological variables. Undoubtedly, any response from the authors would improve their work and facilitate a better understanding for the readers.

Acknowledgements. The authors would appreciate the financial support receiving from Universiti Kebangsaan Malaysia and Ministry of Higher Education.

Edited by: D. Solomatine 


\section{References}

Abrahart, R. J. and See, L.: Comparing neural network and autoregressive moving average techniques for the provision of continuous river flow forecasts in two contrasting catchments, Hydrol. Process., 14, 2157-2172, 2000.

Alhoniemi, E., Hollmen, J., Simula, O., and Vesanto, J.: Process monitoring and modeling using the self-organizing map, Integr. Comp.-Aid. Eng., 6, 3-14, 1999.

Chon, T. S., Park, Y. S., Moon, K. H., and Cha, E. Y.: Patternizing communities by using an artificial neural network, Ecol. Model., 90, 69-78, 1996.
Ismail, S., Shabri, A., and Samsudin, R.: A hybrid model of self organizing maps and least square support vector machine for river flow forecasting, Hydrol. Earth Syst. Sci., 16, 4417-4433, doi:10.5194/hess-16-4417-2012, 2012.

Kohonen, T.: The self-organizing map, Neurocomputing, 21, 1-6, 1998.

Lin, G. and Chen, L.: Identification of homogenous regions for regional frequency analysis using the self-organizingmap, J. Hydrol., 324, 1-9, 2006.

Vesanto, J. and Alhoniemi, E.: Clustering of the self-organizing map, IEEE T. Neural Netw., 11, 586-600, 2000. 